\title{
The anomaly that finally went away?
}

When Archie Cochrane, Fred Moore and I conceived of trying to relate mortality in developed countries to measures of health service provision little did we imagine that it would set a hare running 20 years into the future. ${ }^{1}$ To us this was an amusing correlational study in the spirit of $\mathrm{McKeown}^{2}$ and Illich ${ }^{3}$ - those sceptics of medical prowess. That our work has been reprinted in two collections of epidemiological papers and also as a historical article in this journal is surprising. It is surprising because correlational studies such as these (known nowadays as ecological studies) are at the, despised, bottom of the currently fashionable hierarchy of evidence promulgated, ironically, by the Cochrane Collaboration among others.

The hare was not that a statistical association between health service provision and mortality was absent. Rather it was the marked positive correlation between the prevalence of doctors and infant mortality. Whatever way we looked at our data we could not make that association disappear. Moreover, we could identify no plausible mechanism that would give rise to this association. We were willing to accept that doctors have negligible beneficial impact on mortality rates and I still believe this to be true. However, iatrogenesis on the scale suggested by our findings was implausible. We left others "to extricate doctors from their unhappy position".

Frank Young, whose paper appears in this edition of the journal, claims to have done exactly that. ${ }^{4}$ After reviewing the failed or partially successful attempts of others he puts forward a bold new idea. He hypothesises that growing industrial cities attract an oversupply of doctors and also attract rural immigrants whose health breaks down in the context of city life. Thus, the one will correlate with the other in a non-causal fashion.

Young distinguishes three types of immigration: accepted immigration denoting rural immigrants from within the country, limited immigration denoting foreign "quest workers", and segregated immigration arising from the continuing segregation of peoples where there has been a history of slavery such as in the southern USA. These, he suggests, respectively correspond to decreasing levels of integration into the wider population and thus may represent increasing risks of ill health. He identified three sets of geographical study units each exemplifying one of these types of immigration; these respectively are 47 Japanese prefectures, 29 developed countries including 17 of those used by Cochrane et al, and most counties in the contiguous USA. The analysis proceeds by first attempting to replicate a positive association between doctor provision and mortality and then inserting into the regression equation a variable representing the effect of the particular kind of immigration represented by the group of study units. For example, for the Japanese prefectures a dichotomous variable representing mature versus growing regions is introduced.

A positive, but sometimes weak, association between doctor provision and mortality (infant and age standardised) was found in all three samples. Introducing the proxy variables for immigration into the Japanese and USA data dissolved the associations but did not turn them into negative associations. This procedure did not work with data for the 29 countries but Young identified an issue that makes the validity of those data questionable. Thus, on two apparently distinctly different and quite large sets of data the introduction of a variable derived from the immigration hypothesis removes the association between doctor provision and mortality.

In considering the significance of this two issues arise. Firstly, is Young's hypothesis plausible and, secondly, are his proxy measures of immigration valid? Bearing in mind that the data relate to 1990 it must be presumed that in previous years the migration to cities was taking place and the associated increased doctor provision also occurred. This can be confirmed only by a detailed analysis of demographic trends in Japan and the USA. Nevertheless, it is a testable assumption. Also, one might expect, under the hypothesis, a time trend correlation of mortality and doctor provision in urban centres. The lack of a result in the 29 countries might also be explicable by different demographic trends - and bear in mind that the subset to which the findings of Cochrane at al relate was from 1970 data. The proxy immigration variable in the Japanese data is a crude dichotomy but it has telling impact. The variable used in the USA data is derived by a round about route and should be subject to further scrutiny. However, even if neither is a good proxy for the immigration effect that still begs the question of how they demolish the doctor/mortality association.

Young may have found the answer. But, given the inconsistencies and other uncertainties mentioned above I doubt whether a line will be drawn under the issue yet. Taking his results at face value though a most important finding is that the proxy variables did not lead to a negative doctor/ mortality association. Doctors may be off the hook to some extent but Young's findings do nothing to undermine the thesis of McKeown and in a sense they reinforce it because a clearly spurious association has been dissipated. Young goes further and suggests that his findings call into attention the effects of market forces in the delivery of health care and the effect of structure; matters of some interest to the public health community.

Perhaps of equal interest is the notion that ecological and other correlational studies should not be written off too readily. The dangers of misinterpretation and bias are well known but nevertheless such studies can spark useful debate. Indeed, the companion paper ${ }^{5}$ to Cochrane et al which looked at specific causes of death in the 18 countries led to the continuing research and debate into the cardioprotective effects off wine. Thus, the anonymous author of a dismissive Lancet editorial needs to think again. ${ }^{6}$

SELWYN ST LEGER

University of Manchester, School of Epidemiology and Health Sciences, Medical School, Oxford Road, Manchester M13 9PT, United Kindgdom

1 Cochrane AL, St Leger AS, Moore, F. Health service "input" and mortality "output" in developed countries. If Epidemiol Community Health 1978;32:200-5.

2 McKeown T. The role of medicine: dream, mirage or nemesis. London: Nuffield Provincial Hospital Trust, 1976.

3 Illich I. Medical nemesis - the expropriation of health. London: Calder and Boyars, 1975.

4 Young FW. An explanation of the persistent doctor-mortality association. $\mathcal{F}$ Epidemiol Community Health 2001;55:80-4.

5 St Leger AS, Cochrane, AL, Moore F. Factors associated with cardiac mortality in developed countries with particular reference to the consumption of wine. Lancet 1979;i:1017-20.

6 Anonymous. The anomaly that wouldn't go away. (Editorial). Lancet 1978; ii: 978 